\title{
Long-acting antipsychotic drugs for the treatment of schizophrenia: use in daily practice from naturalistic observations
}

\author{
Giuseppe Rossi ${ }^{1 *+}$, Sonia Frediani ${ }^{2+}$, Roberta Rossi ${ }^{1+}$ and Andrea Rossi ${ }^{3+}$
}

\begin{abstract}
Background: Current guidelines suggest specific criteria for oral or long-acting injectable antipsychotic drugs (LAls). This review aims to describe the demographic and clinical characteristics of the ideal profile of the patient with schizophrenia treated with LAls, through the analysis of nonrandomized studies.

Methods: A systematic review of nonrandomized studies in English was performed attempting to analyze the factors related to the choice and use of LAls in daily practice. The contents were outlined using the Cochrane methods for nonrandomized studies and the variables included demographic as well as clinical characteristics. The available literature did not allow any statistical analysis that could be used to identify the ideal profile of patients with schizophrenia to be treated with LAls.
\end{abstract}

Results: Eighty publications were selected and reviewed. Prevalence of LAl use ranged from $4.8 \%$ to $66 \%$. The only demographic characteristics that were consistently assessed through retrieved studies were age (38.5 years in the 1970 's, 35.8 years in the 1980's, 39.3 years in the 1990's, to 39.5 years in the 2000's) and gender (male > female). Efficacy was assessed through the use of various symptom scales and other indirect measurements; safety was assessed through extrapyramidal symptoms and the use of anticholinergic drugs, but these data were inconsistent and impossible to pool. Efficacy and safety results reported in the different studies yielded a good therapeutic profile with a maximum of $74 \%$ decrease in hospital admissions and the prevalence of extrapyramidal symptoms with LAls consistently increased at 6, 12, 18, and 24 months (35.4\%, 37.1\%, 36.9\%, and 41.3\%, respectively).

Conclusions: This analysis of the available literature strongly suggests that further observational studies on patients with schizophrenia treated with LAls are needed to systematically assess their demographic and clinical characteristics and the relationships between them and patient outcome.

Besides the good efficacy and safety profile of LAls, health care staff must also take into account the importance of establishing a therapeutic alliance with the patient and his/her relatives when selecting the most appropriate treatment. LAls seem to be a good choice not only because of their good safety and efficacy profile, but also because they improve compliance, a key factor to improving adherence and to establishing a therapeutic alliance between patients with schizophrenia, their relatives, and their health care providers.

Keywords: Delayed-action preparations, Antipsychotic agents, Schizophrenia, Patients, Review

\footnotetext{
* Correspondence: g.rossi@fatebenefratelli.it

'Equal contributors

'U.O. Psichiatria, IRCCS "Centro San Giovanni di Dio" Fatebenefratelli, via

Pilastroni 4, Brescia, Italy

Full list of author information is available at the end of the article
} 


\section{Background}

Schizophrenia is a chronic disabling illness with a worldwide lifetime prevalence of about $1 \%$ [1]. It is characterized by relapses alternating with periods of partial or full remission [2] and poor adherence to antipsychotic treatment, leading to multiple rehospitalizations [3] and increased direct and indirect costs [4-11].

Antipsychotic medications have evolved in order to achieve a better control of schizophrenia. Long-acting injectable antipsychotic drugs (LAIs), introduced for the first time in the 1960's, demonstrated their benefits by lowering relapse rates and durations of hospitalization [3,12-14], although the high prevalence and severity of extrapyramidal symptoms (EPS) made it necessary to develop new treatments. Second-generation antipsychotics (SGAs) provided a better tolerability profile compared to the first-generation antipsychotics (FGAs), but a high nonadherence rate was still observed [15]. About 57\% of outpatients treated with oral SGAs adhere to the therapy after 6 months [16]. The efficacy and safety of LAIs have been well established through several randomized controlled trials and therapy choice criteria for these patients have been published recently [17], categorized by disease severity, patients' socioeconomic level, and patients' autonomy.

The recently released LAI SGAs provide the same favorable profile of oral SGAs, with an increased likelihood of improving antipsychotic treatment adherence $[3,13]$.

To determine the ideal profile of the patient suitable for treatment with LAIs, several characteristics should be analyzed in order to understand which of these will predict a better clinical outcome. Relevant information about all these characteristics is available in the literature and important associations between these and LAIs have been established. These features include the following: compliance with and adherence to the treatment [18-21]; attitudes of psychiatrists [22-25], relatives [26], and/or patients $[27,28]$ towards antipsychotic medication; patients' insight about the disease [29-34]; history of relapses [35]; previous treatment with antipsychotic medication [36]; number of previous hospitalizations [3,37]; duration of illness [31]; presence of positive [35] and/or negative [38,39] symptoms; medication-related adverse events [31,40]; and patient experience with medication [41], among others.

Additionally, demographic features such as age, gender, ethnicity, educational background, insurance coverage, polypharmacy, and history of substance abuse should also be taken into account when considering treatment with LAIs [40,42-48].

The ideal candidate for LAI treatment should be a patient who has an unsatisfactory adherence to treatment and who needs to follow a treatment plan ensuring adequate control of the disease, fewer relapses, and good adherence to the treatment-factors that will translate into a better quality of life (QoL), fewer adverse events, fewer rehospitalizations, and a comprehensive improvement. To achieve this goal, a holistic approach has to be established with the aid of health care personnel, patient relatives, and the patients themselves.

The aim of this systematic review is to describe the profile of the ideal patient with schizophrenia to be treated with LAI through the naturalistic observation of age, gender, ethnicity, adherence to and compliance with LAI by both patient and physician and their relative perception of LAI together with treatment efficacy and safety profile.

\section{Methods}

\section{Study design}

A systematic literature review [49] was performed on the data reported in nonrandomized studies for the use of LAIs. The contents of this systematic review were outlined using Cochrane methods for nonrandomized studies [50] in line with the Meta-analysis of Observational Studies in Epidemiology (MOOSE) methods [51]. Nonrandomized studies were chosen because randomized clinical trials, having strict inclusion and exclusion criteria, are not likely to assess clinical judgment of the physicians in the routine clinical practice regarding patients suitable for LAI treatment.

\section{Search strategy}

A comprehensive literature search of the Medline (dating back to 1966), Embase (dating back to 1988), and Cochrane (dating back to 1964) databases was conducted using the OvidSP ${ }^{\circledR}$ interface (Ovid Technologies, Inc:; New York, NY) on May 15, 2011 by the medical information team at Primo Scientific Corporation (Panama City, Panama). The search strategy and results are summarized in Figure 1A. All the possible combinations of the key terms "neuroleptic agent" or "antipsychotic" and "depot" or "long-acting" or "injectable" or "extended release" were employed to obtain relevant reports, regardless of their publication type. The search was then restricted to nonrandomized studies published in English, reporting information on the use of LAIs for the different study variables fulfilling the inclusion criteria (ie, patient demographics; adherence to and compliance with LAI treatment; physician, patient, and relatives perception of LAIs; and the efficacy and safety profiles of LAIs). All the electronic or hard copy publications were retrieved by the library staff of Eli Lilly and Company (Indianapolis, 


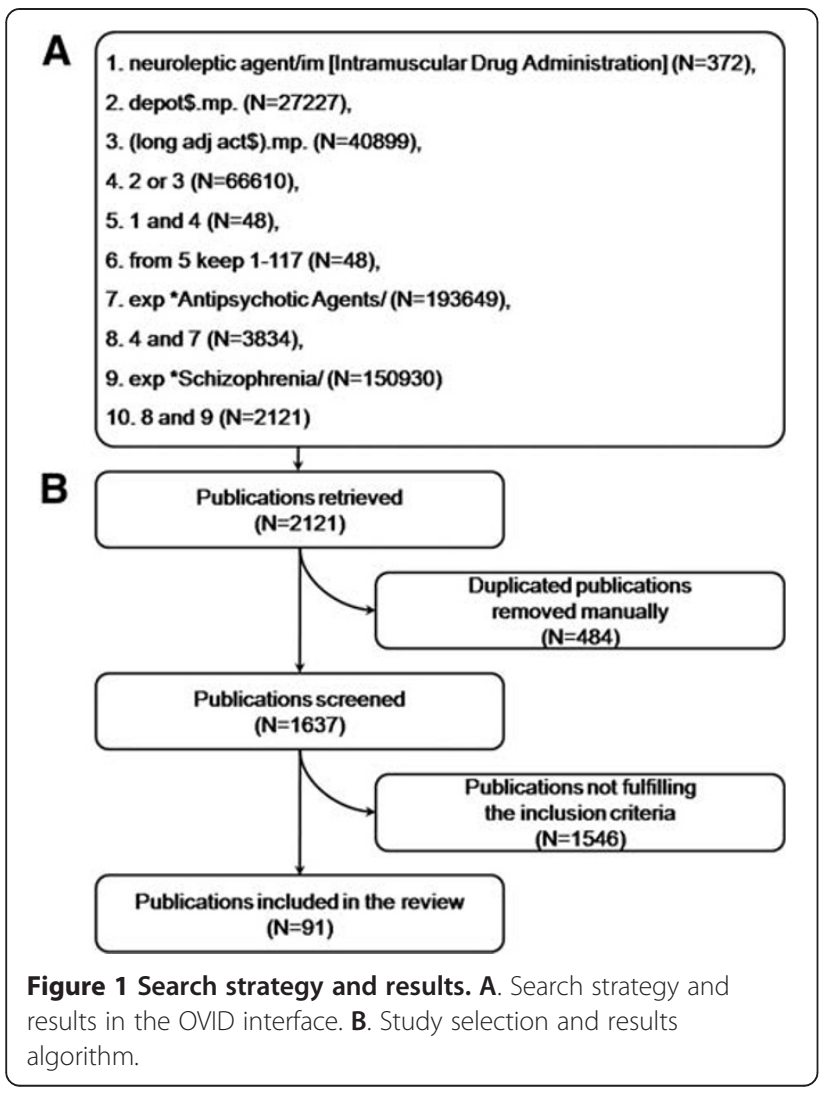

IN) and no abstracts-only or personal communications with the authors were required.

\section{Inclusion and exclusion criteria}

Inclusion criteria were nonrandomized studies (retrospective or prospective, observational, open-label, mirror-image, before and after, and/or case reports/series) in English about the use of LAIs in patients with schizophrenia, schizophreniform disorder, or schizoaffective disorder.

Studies were excluded if they were randomized or double-blind; investigated only pharmacokinetic or pharmacodynamic characteristics of LAIs; patients included were not treated by their psychiatrist according to usual clinical practice; and/or if patients had other psychiatric pathologies.

A flow chart is presented in Figure $1 \mathrm{~B}$ to illustrate the study selection process and results. A detailed list of the studies included is presented in the Additional file 1. Abstracts and full-text articles were screened according to the inclusion and exclusion criteria and the publication full texts were retrieved for those matching the inclusion criteria. Various settings (eg, hospital-based LAI clinics, outpatient clinics) in different countries and populations (eg, young populations, patients in prison, pregnant women) were included in the nonrandomized studies, as these were not restricted by the inclusion criteria.

\section{Statistical analysis}

A formal meta-analysis was not performed because only gender and age were consistently reported throughout the studies and these two characteristics have poor prognostic value to determine which patients benefit the most from the use of LAIs.

The available literature did not allow any statistical analysis that could be used to identify the ideal profile of patients with schizophrenia to be treated with LAIs. Only five of the publications retrieved (all publications derived from the European Schizophrenia Outpatient Health Outcomes [SOHO], a large observational study) included both patients using LAIs and patients using different oral antipsychotics [52-56]. This study did not report any statistical comparisons to assess differences in clinical or demographic characteristics between the two cohorts.

All of the studies retrieved were grouped per publication decade, and the weighted mean age of patients using LAIs was calculated for each decade to assess a possible trend.

\section{Limitations of the study}

1) Study presents nonrandomized studies for the use of LAIs published in English

2) Literature available at resources Medline (dating back to 1966), Embase (dating back to 1988), and Cochrane (dating back to 1964) databases was used in this study

3) There are inconsistencies in reporting the drugs and dosages (in terms of absolute drug concentrations and $\mathrm{mg}$ of chlorpromazine equivalents [CPZE]) used in the different studies

4) Formal quality assessment of study could not be done as studies included are narrative in nature

5) Only gender and mean age are consistently reported among majority of the studies considered

6) Possible selection and information biases may exist as data are derived from nonsystematic, nonrandomized allocation to treatments and the existence of unobserved covariates that might have influenced the outcome

7) Some results were reported in only one paper and thus they must be interpreted/taken with caution

\section{Results}

Eighty publications were included in this analysis (Additional file 1). Several studies assessed the prevalence of LAI use among patients with schizophrenia, which ranged from $11.9 \%$ to $66.0 \%$ [44,45,47,55,57-61]. Because of 
inconsistencies in reporting the drugs and dosages used in the different studies, it was not possible to perform comparisons regarding the doses of LAIs. As this study is narrative in nature [49], demographic and clinical characteristics were grouped without a formal assessment of study quality. All of the studies reporting either type of factors were included and discussed. With these findings in mind, identifying the characteristics of the ideal profile of the patient to receive treatment with LAIs entails analyzing several key demographic and clinical variables, trying to assess the main aspects of efficacy and safety of these drugs.

\section{Demographic aspects}

Only gender and mean age were consistently reported in all of the studies, while other demographic factors were scarcely or inconsistently reported. The studies by Lindström et al., (1996) [57] and Sim et al., (2004) [58] report a higher proportion of male patients $(58.15 \%$ [57]; $55.9 \%$ [58]) treated with LAIs as compared to females $(41.85 \% ; 44.1 \%)$ [57,58]. The calculated mean weighted age at treatment has been mostly stable throughout the decades, from 38.5 years in the 1970's, 35.8 years in the 1980 's, 39.3 years in the 1990's, to 39.5 years in the 2000's. One article [62] reported that older age was associated with lower doses of LAIs $(275 \pm 239 \mathrm{mg}$ CPZE) and, though no significant correlation of age with LAI daily dose for either haloperidol decanoate ( 28 days $3.5 \pm 2.5 \mathrm{mg} ; \mathrm{p}=.50$ ) or fluphenazine decanoate (16 days $1.5 \pm 1.3 ; \mathrm{p}=.70$ ) was found, a pooled analysis of LAIs revealed that patients using them in low doses $(\leq 300 \mathrm{mg}$ CPZE) were significantly older $(\mathrm{p}=.005)$ [44].

In terms of ethnicity, another study [47] reported that African American descent is a stronger predictor of FGA use (odds ratio [OR] 1.53; 95\% confidence interval [CI] 1.12-2.09), at 53\% higher doses (>1000 mg CPZE) than other ethnic groups [48], but less likely $(\mathrm{p}<.001)$ to receive LAIs or oral SGAs.

Results of a prospective comparative study of treatment for schizophrenia conducted from 1997 to 2003 in the use of first-generation depot antipsychotic at any time during the three-year study $(\mathrm{N}=569)$ and those treated with only oral antipsychotics $(\mathrm{N}=1,617)$ showed a low-education background $(\mathrm{p}<.001)$ and poor insurance coverage $(p=.009)$ and further these were also reported to be significantly different among patients using LAIs versus oral antipsychotics (75\% vs. 66\% and $6 \%$ vs. 8\%) [47]. Polypharmacy was also frequently reported [44] in patients with schizophrenia on LAI treatment and is a predictor for lower doses of antipsychotic drugs (OR 0.42; 95\% CI 0.40-0.44; p<.001). Remington et al. [63] found differences in the setting where patients were treated: a large provincial hospital with 325 beds mostly devoted to treating patients with schizophrenia used significantly higher doses $(\mathrm{p}=.05)$ of antipsychotic drugs $(\mathrm{N}=58$; dose $773.8 \pm 784.6 \mathrm{mg}$ CPZE) when compared to a university-affiliated psychiatric teaching hospital with 85 beds $(\mathrm{N}=52$; dose 424.8 $\pm 317.2 \mathrm{mg} \mathrm{CPZE}$ ), and to a 25-bed inpatient psychiatric unit $(\mathrm{N}=53$; dose: $355 \pm 283.1 \mathrm{mg} C P Z E)$, respectively. Conventional and depot antipsychotic medication were the ones mostly used at provincial hospitals (99\%; 43\%), while the novel antipsychotics were the most commonly used at university and community hospitals (56\%; 55\%) [63]. Patients on LAIs were also found to receive higher doses of neuroleptic drugs in terms of chlorpromazine equivalent doses (525 mg CPZE; $\mathrm{p}<.001)$ [61].

\section{Clinical aspects}

Several key clinical elements are reported as being associated with the use of antipsychotic treatment for schizophrenia.

\section{Perception of LAls}

Less than $20 \%$ of patients with schizophrenia receive LAIs and less than $10 \%$ of psychiatrists offer LAIs after a first psychotic episode, prescribing them in a very conservative manner and only when other therapeutic options have failed [26], even though there is no evidence supporting this practice [64]. It is important to note that psychiatrists have decreased their LAI prescribing rates in the last five years by approximately $50 \%$, although LAIs are shown to be very efficacious, are associated with higher compliance rates, and are currently more available [25]. A questionnaire-based survey of 198 German psychiatrists found that LAI was only prescribed to $13.3 \%$ out of $26.7 \%$ of patients with first episode schizophrenia [65]. Principal reasons for lower prescription rate were: difficulty in presenting the benefits of LAI to patients for first treatment option; poor availability of the LAI version of risperidone, olanzapine pamoate, and paliperidone palmitate $[22,25,66]$, specifically preferred second generation LAI antipsychotics [AP2G] [67,68]; and lower preference of psychiatrists for prescribing LAI due to perception of adverse effects of depot antipsychotics and related impact on the relationship with the patient [65].

Psychiatrists prescribe oral tablet antipsychotics $88 \%$ of the time [26]. When LAIs are prescribed, SGAs are preferred (66\%) over FGAs for LAI-naïve patients [25]. There is a report of patients having lower relapse rates after using LAI risperidone after 2 years of treatment following their first episode of psychosis [64].

Regarding patient attitudes toward LAI formulations, $24 \%$ of patients reported LAIs as their first choice of treatment, while $88 \%$ reported the acceptance of oral 
tablets as their first choice. There is a marked contrast when the patients are separated into three different groups (LAI-naïve patients, patients currently receiving LAIs, and patients previously treated with LAIs). LAInaïve patients preferred oral tablets over LAIs ( $94 \%$ vs. $23 \%$ ), whereas patients on LAI treatment chose it over oral tablets (73\% vs. 67\%). Compared to LAI-naïve patients, patients with previous LAI experience chose LAI more often, but curiously, had a greater preference for tablet formulations [36].

The results from a clinical survey evaluating the prescription rate of antipsychotics by psychiatrists corroborated the belief that patients with a poor course of schizophrenia fit the ideal profile to receive LAI treatment [69].

Patients with a better course of illness are characterized by having good insight about their illness, high educational levels, high levels of participation in treatment decisions, knowledge of their condition, and a desire to maintain a therapeutic alliance with the psychiatrist. A new approach could also include these patients as candidates to receive LAIs [45]. Many studies have reported that patients with better relationships with their physicians have better compliance rates compared to those with "fair" or "poor" relationships ( $74 \%$ vs. $26 \%$, respectively) $[21,70]$.

There is a high prevalence of poor insight among patients with schizophrenia [71]. Poor insight is the most common symptom of schizophrenia [34]; approximately $57 \%$ of patients are moderately or severely unaware of having a mental illness [33]. Poor insight has been related to poor compliance [72], which is the main cause of nonadherence to treatment in patients with schizophrenia [73]. The consequences of poor patient insight about their illness are reflected in a greater risk of relapse and more frequent and longer hospital admissions [21]. Treatment with LAI risperidone improved insight scores in patients previously treated with oral SGAs or typical LAIs. Additionally, insight improvement corresponded to favorable changes in other symptom domains, such as the Positive and Negative Symptoms Scale (PANSS) and the Clinical Global Impression (CGI)-Severity subscale [71].

\section{Adherence to and compliance with LAI treatment}

Nonadherence rates with antipsychotics are often reported as being 40\%-60\% [74,75]. When comparing treatment adherence to preference between patients on oral antipsychotic tablets or LAIs, patients prescribed with LAIs were significantly more compliant than those receiving oral antipsychotics [11,27,40,76-78]. Figure 2 presents an algorithm of compliance predictors, that can help the mental-health specialists choose the best next step in the management of patients with schizophrenia on treatment, taking into consideration the most relevant aspects found in the literature. These predictors must be incorporated into the concept that all those involved in the integral care of the patient with schizophrenia must engage in a therapeutic alliance [21].

\section{Efficacy}

The efficacy of LAIs in general, and SGAs in particular, seems to be consistently shown throughout studies where patients reported improvement on the most common efficacy measures.

One such measure is the CGI scale, which has become one of the most widely used assessment tools in psychiatry since it was first published [79]. A greater baseline overall CGI score was found to be a predictor of discontinuation for antipsychotic medication [54]. Studies report that CGI scales significantly improved in patients using LAI SGAs $[52,53,55,56,80]$, zuclopenthixol decanoate [81], perphenazine decanoate [82,83], or LAI risperidone $[84,85]$. PANSS, which is not an outcome rating instrument per se, but originated from the growing need to reduce the heterogeneity of what was known about schizophrenia, [86] was also used in observational studies [87]. PANSS score also consistently improved in studies where LAI risperidone was used $[88,89]$. The Comprehensive Psychiatric Rating Scale (CPRS) has also been used in another study [90], reporting significant correlations $(\mathrm{p}<.001)$ with the serum levels of zuclopenthixol decanoate.

Other authors have attempted to evaluate the QoL experienced by patients using LAIs. This has been assessed by different studies using various scales, such as the Global Assessment of Functioning (GAF), the Short Form Health Survey (SF-36), and the EuroQoL 5Dimensions Visual Analog Scale (EQ-VAS). Studies on the use of LAIs in different settings have reported significant improvements $(\mathrm{p}<.01)$ in the total GAF score [47,79,91-94] or in the SF-36 overall score [95], as well as in some of its items $[71,84,91,93,96]$. Although the use of the EQ-VAS, another scale for assessing QoL used through the $\mathrm{SOHO}$ cohorts, has not yielded significant improvements in QoL for all pooled LAIs $[52,53]$, its baseline value has been found to be a significant factor associated with achieving long-lasting symptomatic remission (OR 1.026; 95\% CI not reported; $\mathrm{p}<.0001)$ [56].

An indirect measurement of efficacy is the hospitalization rate which, despite having different operational definitions, improved in patients treated with LAIs. Studies of treatment with LAIs consistently report significant decreases in the different quantifiers expressing the length of hospitalization (ie, absolute hospital days, days per patient, number of hospitalizations, bed-days per patient, or 
number of hospitalizations per patient) [9,47,80,85,97-106]. Only one small study $(n=46)$ found no statistical differences in rehospitalization rates between patients using oral antipsychotics versus LAIs [107]. A greater length of hospitalization was related to an increased number of prescriptions of LAIs versus oral antipsychotics and the history of psychiatric hospitalization in the prior year was a predictor of LAI FGA use [47]. The frequency of previous admissions was a predictor of rehospitalizations in a oneyear observational trial [98]. The annual risks of readmission for patients using fluphenazine decanoate or haloperidol decanoate were $21 \%$ and $35 \%$, respectively [46] and a decrease in rehospitalization rates was reported in studies with LAI fluphenazine (74\% decrease in hospital admissions compared with previous treatment) [105], perphenazine (59\% decrease in relative risk compared with haloperidol) [108]; and LAI risperidone (27\% reduction in hospitalization rates) [9]. Patients using haloperidol decanoate presented statistically significantly greater differences in rehospitalization risk when compared to oral risperidone (Holm's adjusted $\mathrm{p}=.001$ ), olanzapine (Holm's adjusted $\mathrm{p}=.0008$ ), and clozapine (Holm's adjusted $\mathrm{p}=.049$ ) [46]. Frequency of hospitalizations was positively related with duration of illness, with current dose of neuroleptics (i.e., fluphenazine), and with overall neuroleptic exposure [109].

\section{Safety}

Many patients switching to LAI risperidone after treatment with conventional antipsychotics showed a significant improvement in EPS, measured primarily by the Extrapyramidal Symptom Rating Scale (ESRS) [90,91,93,95,96,110-113]. The ESRS has also been used in patients treated with perphenazine decanoate $[82,83]$ and fluphenazine decanoate [114] with similar results. When the Drug-Induced EPS Scale (DIEPSS) was applied to patients treated with LAI risperidone, no significant differences were found in the rate of EPS [94]. In the SOHO study [53], the prevalence of EPS in the Italian cohort treated with LAIs consistently increased at 6, 12, 18, and 24 months (35.4\%, 37.1\%, 36.9\%, and $41.3 \%$, respectively). In the same cohort, the proportion of EPS at 12 months was significantly higher in patients treated with typical LAIs (32\%) and oral typical antipsychotics (30\%) compared to risperidone (16\%), quetiapine (10\%), clozapine (9\%), and olanzapine (8\%) [52]. Among patients with or without EPS treated with typical LAIs, the GAF and total BPRS scores differed at hospital discharge [115]. An indirect measure of EPS is the use of anticholinergic drugs, which was reported as significantly higher in patients using LAIs (47\%) compared with patients using oral SGAs (13\%) [116] and has a rate ranging from $30.9 \%$ to $32.0 \%$ 
for overall LAIs [52,117]. Lower values of anticholinergic drug use were reported in patients using LAI risperidone (5.2\%) [118] and higher values were reported in those using fluphenazine decanoate (67.0\%) [114]. Common EPS and non-EPS adverse events and their frequencies are summarized in Tables 1 and 2, respectively. The largest report on prolactin-related adverse events was found in the Italian cohort of the SOHO study $(n=3016)$ [52] after 12 months of treatment with different antipsychotic drugs (risperidone, quetiapine, clozapine, typical oral antipsychotic drugs, and typical LAI). A significant proportion of patients using typical LAIs reported prolactin-related adverse events, the most common being loss of libido, which was reported by $38.1 \%$ of these patients.

For LAIs, small but statistically significant increases in body weight and BMI have been reported; contrasting reports of nonsignificant increases in these parameters were also found in the literature (Table 3). These weight and BMI increases were not dose-dependent [117].

Pain caused by injections is another safety measure reported that is most often evaluated through the visual analog scale (VAS). One study [119] found that zuclopenthixol injections were significantly more painful than flupenthixol, fluphenazine, and haloperidol and that pain score measured by VAS was correlated to the Hamilton Scale for Depression (HAM-D). Another study found that injection-site pain with LAI risperidone significantly decreased over 50 weeks [96]. An additional LAI pooled study (haloperidol, fluphenazine, zuclopenthixol, and flupenthixol) found no significant correlation between VAS measures 5 minutes after the injection, but found a significant correlation after 2 days of the injection administration [119]. No relationship was found between VAS pain score, patient weight, or the score in the Udvalg for Kliniske Undersøgelser (UKU) 48-Item Side-Effect Rating Scale [8].

Some studies report the results while using LAIs in peculiar situations. One report [120] on the use of LAI risperidone during pregnancy was found, and it did not report any immediate complication at birth. Another study [121] found that mean serum copper levels were significantly $(\mathrm{p}=.004)$ higher in patients treated with fluphenazine decanoate $(117.4 \mu \mathrm{g} / \mathrm{dL} ; 95 \%$ CI 111.2$123.6 \mu \mathrm{g} / \mathrm{dL})$ versus healthy controls $(105.6 \mu \mathrm{g} / \mathrm{dL} ; 95 \%$ CI 96.9-114.2 $\mu \mathrm{g} / \mathrm{dL})$; mean serum zinc levels did not differ between the two groups.

\section{Discussion}

Long-acting injectable antipsychotic drugs were developed to become a therapeutic option especially for those patients where nonadherence is a major clinical concern, with consequences of subsequent relapse episodes and rehospitalizations $[46,122,123]$. Although there is a strong, but perhaps misguided, belief that LAIs cannot be used as first-line treatment for schizophrenia, new guidelines state that the clinician should consider offering them to LAI-naïve patients with schizophrenia [124131].

The most favorable conditions for the development of an effective therapeutic alliance occur in patients who are well-informed about their illness and are compliant with treatment, in conjunction with medical staff who are willing to provide explanations and to offer a holistic therapeutic approach [132-134]. This type of therapeutic alliance promotes the patient's adherence to their treatment and facilitates open lines of communication, so that patients can meaningfully participate in treatment decisions.

Even though nonrandomized studies have some wellknown limitations (uncertainty of data collected, differences in their design and implementation, lower level of evidence than randomized controlled studies, and not being included in study registries) [50], they are the only studies in which patients were enrolled and treated according to physicians' clinical judgment. Consequently, nonrandomized studies are the only studies that, in a naturalistic setting, allow researchers to understand how physicians, based on their clinical judgment, select patients with schizophrenia who have the ideal profile for LAI treatment and who should benefit the most from it. Moreover, they provide naturalistic observation of

Table 1 Percentages of extrapyramidal adverse events reported for different long-acting antipsychotic drugs

\begin{tabular}{|c|c|c|c|c|c|c|c|c|c|c|c|c|c|}
\hline Drug & $\mathrm{FL}$ & $\mathrm{FE}$ & $\mathbf{R}$ & $\mathbf{R}$ & $\mathbf{R}$ & $R y$ & $\mathrm{R} \mathrm{a}$ & $\mathbf{R}$ & $\mathbf{R}$ & $\mathbf{P}$ & $\mathbf{V}$ & V & $\mathbf{Z}$ \\
\hline Reference & {$[131]$} & [132] & {$[80]$} & [132] & [90] & {$[91]$} & [91] & {$[107]$} & {$[133]$} & {$[77]$} & [8] & [58] & {$[76]$} \\
\hline n & 16 & 5 & 19 & 87 & 249 & 66 & 351 & 725 & 529 & 42 & 53 & 368 & 19 \\
\hline Dystonia & - & - & - & 1.1 & - & - & - & - & - & - & 15.1 & 0.5 & - \\
\hline Akathisia & 12.5 & 40.0 & 5.3 & 2.3 & 2.0 & 19.7 & 11.1 & 17.0 & 3.4 & - & 43.4 & 2.4 & - \\
\hline Parkinsonism/tremor & 6.2 & - & - & 4.6 & - & - & - & - & 6.0 & 2.4 & 30.2 & 7.6 & - \\
\hline Tardive dyskinesia & - & - & - & 3.4 & - & - & - & - & - & - & - & 3.0 & 15.8 \\
\hline Hypertonia & - & - & - & 2.3 & - & - & - & - & - & - & 24.5 & - & - \\
\hline
\end{tabular}

Abbreviations: $Z=$ zuclopenthixol decanoate; $R=$ risperidone; $y=$ in young patients; $a=$ in adult patients; $F L=$ flupenthixol; $F E=$ fluphenazine; $V=$ various long-acting antipsychotic drugs; $-=$ not reported. 
Table 2 Percentages of the most frequent and selected general adverse events reported for different long-acting antipsychotic drugs

\begin{tabular}{|c|c|c|c|c|c|c|c|c|c|c|c|c|c|c|c|c|c|c|}
\hline Drug & $\mathrm{FL}$ & $\mathbf{R}$ & $\mathbf{R}$ & $\mathbf{R}$ & $R$, in no $r$ & $R$ in $r$ & $\mathbf{R}$ & $\mathrm{R}$ vs oral & $\mathbf{R}$ & $\mathbf{R}$ & R y & $\mathrm{R} \mathbf{a}$ & $\mathbf{R}$ & $\mathbf{R}$ & $\mathbf{R}$ & $\mathbf{R}$ & v & Z \\
\hline Reference & [131] & {$[15]$} & {$[79]$} & {$[86]$} & [84] & [84] & [85] & {$[88]$} & [89] & {$[90]$} & {$[91]$} & {$[91]$} & {$[105]$} & {$[107]$} & [132] & [133] & {$[88]$} & {$[76]$} \\
\hline $\mathbf{n}$ & 16 & 715 & 192 & 202 & 312 & 82 & 1476 & 100 & 40 & 249 & 66 & 351 & 336 & 725 & 87 & 529 & 565 & 19 \\
\hline Anxiety & 12.5 & 12 & 12 & 15 & 28.7 & 24.5 & 6.9 & 11.0 & - & 11 & 21 & 23 & 22.3 & 26 & 16.1 & 23.9 & - & - \\
\hline Insomnia & 6.2 & 10 & 9 & 9 & 26.5 & 25.0 & 7.0 & 9.0 & 5.0 & 6 & 29 & 19 & 23.5 & 22 & 16.1 & 18.7 & - & 8 \\
\hline Disease exacerbation & - & - & 10 & - & 20.1 & 15.8 & 6.1 & 5.0 & - & 6 & 12 & 12 & 18.2 & 15 & 19.5 & 7.4 & - & 一 \\
\hline Depressive reactions & 17 & - & 6 & - & 19.8 & 15.7 & - & 5.0 & - & - & 17 & 14 & 19.3 & 15 & - & 11.3 & - & 25 \\
\hline Headache & - & - & - & - & 14.7 & 14.7 & - & - & 2.5 & 6 & 21 & 11 & & - & 11.5 & 7.7 & - & - \\
\hline Gl symptoms ${ }^{a}$ & - & - & - & - & - & - & - & - & - & - & 11 & 3 & - & - & - & - & - & 17 \\
\hline Glucose-related AEs & - & - & - & $0.5^{\mathrm{b}}$ & - & - & - & - & - & - & - & - & - & - & 0.0 & $0.8^{c}$ & 0.0 & 一 \\
\hline Prolactin-related $A E s^{d}$ & - & - & - & 0.5 & - & - & - & 6.0 & $2.5^{f}$ & 2.8 & - & - & - & - & - & - & $0.4^{e}$ & - \\
\hline Sedation/Somnolence & - & - & - & - & - & - & - & - & - & - & 12 & 5 & - & - & - & - & - & - \\
\hline Rhinitis & - & - & - & - & - & - & - & - & - & - & 18 & 11 & - & - & - & - & - & - \\
\hline Fatigue & - & - & - & - & - & - & - & - & - & - & 15 & 7 & - & - & - & - & - & - \\
\hline Others & $6.2^{h}$ & - & - & - & - & - & - & - & $2.5^{\mathrm{g}, \mathrm{h}}$ & - & - & 一 & - & - & - & - & - & $17^{\mathrm{h}}$ \\
\hline
\end{tabular}

Abbreviations: $F L=$ flupenthixol; $R=$ risperidone; $r=$ remission; $y=$ in young patients; $a=$ in adult patients; $V=$ various; $Z=$ zuclopenthixol decanoate;

$G I=$ gastrointestinal; $A E s=$ adverse events; $-=$ not reported.

ancludes dyspepsia, nausea, and vomiting.

${ }^{b}$ New onset type 2 diabetes mellitus $(n=1)$.

${ }^{c}$ New onset type 2 diabetes mellitus $(n=3)$ and hyperglycemia $(n=1)$.

dincludes loss of libido, sexual impotence, galactorrhea, and gynecomastia.

Impotence $(n=1)$ and galactorrhea $(n=1)$.

${ }^{f}$ Irregular menstruation $(n=1)$.

${ }^{9}$ Disturbances in accommodation.

hDizziness.

efficacy, safety and compliance to the treatment chosen by the physician as the most appropriate for each patient.

We found no obvious explanation for the decrease in the prescription rates of LAIs by psychiatrists $[25,57,135]$ even when LAIs have specific advantages over oral FGAs and SGAs, especially in noncompliant patients $[136,137]$. This could also be due to the perception that depots and LAIs are old-fashioned and they are reserved for the most chronic and disabled patients [138-140]. Furthermore, due to higher availability of oral atypical antipsychotics in the 1990s, with associated heavy marketing, the decline in prescription of depot has continued due to the assumptions that patients always prefer oral to depots even though clinician's attitude towards these medications is marginally improved. The adverse impacts of patient preference of depots to LAIs, in relation to relapse prevention are rarely explained and discussed with the patient [141]. A sixmonth, open-label study with LAI risperidone in 382 patients with recent schizophrenia or schizoaffective disorder (diagnosed $\leq 3$ years ago) showed significant decrease of severity of schizophrenic symptomatology in $73 \%$ : among these, in $40 \%$ of patients, total PANSS score decreased by at least $20 \%$. At the same time, patients showed an improvement of overall functioning, quality of life, and satisfaction [142,143]. These observations suggest that there is a need for prescribing LAI for effecting an increase in efficacy and functioning.

Even when the validity of using certain scales as efficacy endpoint measurements has been criticized $[86,87]$, these and other efficacy endpoints such as good symptomatic control, improved QoL, and reduced hospitalization rates seem to be consistently achieved by patients with schizophrenia treated with LAIs.

Safety, which can be evaluated using different tools, might be a concern when considering the use of LAIs. The frequency of EPS seems to be reduced when patients switch from oral to LAIs and the most frequent EPS reported were akathisia and parkinsonism/tremor (Table 1). Tardive dyskinesia was generally reported less frequently, but was more commonly reported in patients using zuclopenthixol decanoate than those using LAI risperidone or LAIs in general [81]. Other frequently reported side effects of LAIs are anxiety, insomnia, disease exacerbation, depression, headache, and weight gain, but the data retrieved cannot be considered conclusive. It is fundamental to consider side effects, since patient attitude towards these strongly influence their attitude towards the entire treatment [8].

Unfortunately, the data reported in the literature cannot be combined any further to identify the ideal 
Table 3 Weight and BMI changes reported in selected LAI publications

\begin{tabular}{|c|c|c|c|c|}
\hline LAI(s) used & Reference & $\mathrm{n}$ & $\begin{array}{l}\text { Weight change, } \\
\text { mean difference, } \\
\text { kg }\end{array}$ & $\begin{array}{c}\text { BMI change, } \\
\text { mean difference, } \\
\mathrm{kg} / \mathrm{m}^{2}\end{array}$ \\
\hline Risperidone & [15] & 715 & $1.4^{* * *}$ & $0.5^{* * *}$ \\
\hline Various & [48] & 293 & $0.0^{\mathrm{a}}$ & NR \\
\hline Various & {$[52]$} & 176 & 0.1 & NR \\
\hline Various & [53] & 540 & $2.9^{b}$ & $0.7^{\mathrm{b}}$ \\
\hline Various & [55] & 1173 & NR & $0.2^{\mathrm{b}}$ \\
\hline Various & [58] & 2399 & $-1.0^{\mathrm{b}}$ & $N R$ \\
\hline Various & [61] & 534 & $1.3^{c}$ & NR \\
\hline Perphenazine & [78] & 42 & No weight change ${ }^{d}$ & $N R$ \\
\hline Risperidone & [79] & 192 & 0.0 & -0.1 \\
\hline Risperidone & [85] & 1476 & 0.9 & 0.3 \\
\hline Risperidone & [86] & 202 & 0.5 & 0.2 \\
\hline Various & [88] & 565 & $0.9^{*}$ & NR \\
\hline Risperidone & [90] & 249 & $1.4^{* * *}$ & $0.5^{* * *}$ \\
\hline Risperidone & {$[105]$} & 336 & 2.5 & 0.8 \\
\hline Risperidone & [108] & 50 & NR & 0.0 \\
\hline Various & [112] & 97 & NR & $1.5^{\mathrm{b}}$ \\
\hline Risperidone & [132] & 67 & -0.3 & NR \\
\hline Risperidone & [133] & 529 & $1.0^{* * *}$ & $0.6^{* * *}$ \\
\hline Various & [134] & 5950 & $N R$ & $-0.7^{\mathrm{e}}$ \\
\hline
\end{tabular}

Abbreviations: $B M I=$ body mass index; $L A I=$ long-acting injectable

antipsychotic drugs; $N R=$ not reported; $p t s=$ patients.

${ }^{\text {a }}$ ts treated with in-range chlorpromazine-equivalent doses versus patients

treated with higher chlorpromazine-equivalent doses.

bersus oral antipsychotics.

${ }^{\mathrm{c}}$ Pts treated with LAI and anticholinergic drugs versus patients treated with LAI without anticholinergic drugs.

${ }^{\mathrm{d}}$ This study reported no weight change, with 16 pts gaining a range of 1-9 kg and 7 pts losing a range of $1-2 \mathrm{~kg}$.

epatients achieving persistent remission versus patients with prolonged disease.

$\mathrm{p} \leq .05 ;{ }^{* *} \mathrm{p} \leq .01 ;{ }^{* * *} \mathrm{p} \leq .001$.

profile of the patient using LAIs, due to the inconsistency in the way the results are reported. Even those variables, such as age and gender, reported in all studies retrieved have poor prognostic value in terms of understanding how physicians select the ideal profile of the patient with schizophrenia to be treated with LAIs. The only consistently reported reason why certain patient profiles are identified as "ideal" to receive LAI treatment is because this type of administration ensures treatment delivery. Patient insight, attitude toward, and compliance with LAIs are crucial factors that influence physician's LAI choice, especially when a good therapeutic alliance has been established $[69,144]$. Nowadays, the therapeutic alliance seems to be the most influential factor related to successful compliance and adequate adherence to the schizophrenia treatment $[16,26,28,43,69]$. This factor can improve efficacy, safety, and cost-effectiveness outcomes (Figure 2) [5-7,9,69,122].

Authors agree that the most common reason for prescribing LAIs is noncompliance, but these drugs on their own do not overcome the problem of treatment nonadherence. This is why therapeutic alliance plays a key role $[16,26,28,43,69]$. Greater illness insight is related to better attitudes toward treatment, improved compliance, and fewer relapses and hospitalizations [29,30]. Patients' and their relatives' opinions must be taken into consideration before initiating or switching to a new therapeutic plan. A survey among patients with schizophrenia revealed that $67 \%$ of them had not received any information about LAI treatment from their psychiatrists [25]. Ultimately, patients have the right to make an informed decision about LAI treatment. Its overall negative perception could be reduced if psychiatrists were to provide broader and more comprehensive information to patients with schizophrenia and their relatives. Furthermore, patients' decisions regarding treatment should be guided by healthcare providers (Figure 3 ), after the most relevant topics and concerns have been evaluated, discussed and understood by the patients and their relatives.

\section{Conclusions}

Though LAI prescription rates have been decreasing, they still prove to have good efficacy and safety profiles. The important question, therefore, is to determine which patients with schizophrenia are the most suitable for treatment with LAIs. Our research might reveals indicators that could support psychiatrists tailor their answer to this question when dealing with particular cases. Psychiatrists seeking to improve the therapeutic alliance with patients who need to improve treatment compliance and adherence should consider LAIs when establishing a therapeutic plan. Efficacy and safety must also be taken into account. Naturalistic setting trials aimed at understanding how therapeutic alliance can be improved by the use of LAIs should be carried out in order to systematically identify those patients who would most benefit from the use of LAIs.

\section{Additional file}

Additional file 1: Observational studies included in the data analysis. This data table includes the 80 studies that fulfilled the inclusion criteria for this review and their general description.

Competing interests

This article was sponsored by Eli Lilly and Company.

Giuseppe Rossi and Sonia Frediani have acted as invited speakers for Eli Lilly. Andrea Rossi is a full time employee at Eli Lilly Italy.

Roberta Rossi declares no conflicts of interest. 


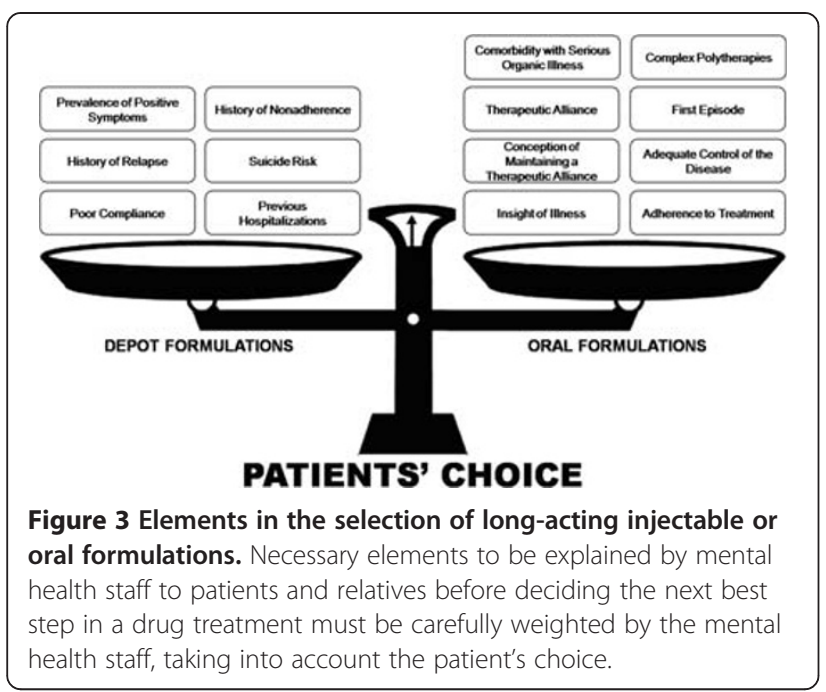

\section{Authors' contributions}

GR designed the article structure, substantially revised it and provided all clinical guidance's from retrieved literature.SF and RR contributed to the study design, literature revision and selection, and provided clinical decision guidelines. AR performed literature search, contributed in writing the article, revised and selected retrieved literature. All authors approved the final version of this article.

\section{Acknowledgements}

We would like to acknowledge the medical writing assistance provided by Humberto López Castillo, MD, MSc, MEd, and Sudha Kondapi, MSc, MTech, of PRIMO Scientific Corporation, Panama City, Republic of Panama.

\section{Author details}

'U.O. Psichiatria, IRCCS "Centro San Giovanni di Dio" Fatebenefratelli, via Pilastroni 4, Brescia, Italy. ${ }^{2}$ Centro di Salute Mentale La Badia U.S.L. 11, Empoli, Italy. ${ }^{3}$ Medical Dept. Eli Lilly Italy, Via Gramsci 731, Sesto Fiorentino (FI), Italy.

Received: 15 December 2011 Accepted: 1 August 2012

Published: 21 August 2012

\section{References}

1. Epi Database ${ }^{\circledR}:$ Kantar Health. Available from www.epidb.com. Accessed 20 Jul 2011.

2. Davis JM: Overview: maintenance therapy in psychiatry: I. Schizophrenia. Am J Psychiatry 1975, 132:1237-1245.

3. Schooler NR: Relapse and rehospitalization: comparing oral and depot antipsychotics. J Clin Psychiatry 2003, 64:14-17.

4. Knapp M: Schizophrenia costs and treatment cost-effectiveness. Acta Psychiatr Scand Suppl 2000, 407:15-18.

5. McEvoy JP: The costs of schizophrenia. J Clin Psychiatry 2007, 68(Suppl 14):4-7.

6. Law WL, Hui HY, Young WM, You JHS: Atypical antipsychotic therapy for treatment of schizophrenia in Hong Kong Chinese patients-a cost analysis. Int J Clin Pharmacol Ther 2007, 45:264-270.

7. Dernovsek MZ, Prevolnik Rupel V, Rebolj M, Tavcar R: Quality of life and treatment costs in schizophrenic outpatients, treated with depot neuroleptics. Eur Psychiatry 2001, 16:474-482.

8. Larsen EB, Gerlach J: Subjective experience of treatment, side-effects, mental state and quality of life in chronic schizophrenic out-patients treated with depot neuroleptics. Acta Psychiatr Scand 1996, 93:381-388.

9. Willis M, Svensson M, Löthgren M, Eriksson B, Berntsson A, Persson U: The impact on schizophrenia-related hospital utilization and costs of switching to long-acting risperidone injections in Sweden. Eur J Health Econ 2010, 11:585-594.

10. Knapp MRJ: Measuring the economic benefit of treatment with atypical antipsychotics. Eur Psychiatry 1998, 13(Suppl 1):37s-45s.
11. Ahn J, McCombs JS, Jung C, Croudace TJ, McDonnell D, Ascher-Svanum H, Edgell ET, Shi L: Classifying patients by antipsychotic adherence patterns using latent class analysis: characteristics of nonadherent groups in the California Medicaid (Medi-Cal) program. Value Health 2008, 11:48-56.

12. Davis JM, Kane JM, Marder SR, Brauzer B, Gierl B, Schooler N, Casey DE, Hassan M: Dose response of phrophylactic antipsychotics. J Clin Psychiatry 1993, 54:24-30.

13. Davis JM, Matalon L, Wantanabe MD, Blake L, Matalon L: Depot antipsychotic drugs. Place in therapy. Drugs 1994, 47:741-773.

14. Gitlin M, Nuechterlein K, Subotnik KL, Ventura J, Mintz J, Fogelson DL, Bartzokis G, Aravagiri M: Clinical outcome following neuroleptic discontinuation in patients with remitted recent-onset schizophrenia. Am J Psychiatry 2001, 158:1835-1842.

15. Kissling W, Heres S, Lloyd K, Sacchetti E, Bouhours P, Medori R, Llorca PM: Direct transition to long-acting risperidone-analysis of long-term efficacy. J Psychopharmacol 2005, 19:15-21.

16. Dolder CR, Lacro JP, Dunn LB, Jeste DV: Antiphsychotic medication adherence: is there a difference between typical and atypical agents? Am J Psychiatry 2002, 159:103-108.

17. Correl CU, Cañas S, Larmo I, Levy P, Montes JM, Fagiolini A, Papageorgiou G, Rossi A, Sturlason R, Zink M: Individualizing antipsychotic treatment selection in schizophrenia: characteristics of empirically derived patient subgroups. Eur Psychiatry 2011, 26:3-16.

18. David AS: Treatment adherence in psychoses. Br J Psychiatry 2010, 197:431-432.

19. Kane JM: Strategies for improving compliance in treatment of schizophrenia by using a long-acting formulation of an antipsychotic: clinical studies. J Clin Psychiatry 2003, 64:34-40.

20. Keith SJ, Kane JM: Partial compliance and patient consequences in schizophrenia: our patients can do better. J Clin Psychiatry 2003, 64:1308-1315

21. Perkins DO: Predictors of noncompliance in patients with schizophrenia. J Clin Psychiatry 2002, 63:1121-1128

22. Heres S, Hamann J, Kissling W, Leucht S: Attitudes of psychiatrists toward antipsychotic depot medication. J Clin Psychiatry 2006, 67:1948-1953.

23. Leucht S, Heres S: Epidemiology, clinical consequences, and psychosocial treatment of nonadherence in schizophrenia. J Clin Psychiatry 2006, 67:3-8.

24. Leucht S: Psychiatric treatment guidelines: doctors' non-compliance or insufficient evidence? Acta Psychiatr Scand 2007, 115:417-419.

25. Patel MX, Haddad PM, Chaudhry IB, McLoughlin S, David AS: Psychiatrists' use, knowledge and attitudes to first- and secondgeneration antipsychotic long-acting injections: comparisons over 5 years. J Psychopharmacol 2010, 24:1473-1482.

26. Jaeger M, Rossler W: Attitudes towards long-acting depot antipsychotics: a survey of patients, relatives and psychiatrists. Psychiatry Res 2010, 175:58-62.

27. Hovens JE, Roman B, Van Dinther R: Patients with schizophrenia prefer long-acting injections. Schizophr Res 2006, 81(Suppl):S84.

28. Kikkert MJ, Schene AH, Koeter MWJ, Robson D, Born A, Helm H, Nose M, Goss C, Thornicroft G, Gray RJ: Medication adherence in schizophrenia: exploring patients', carers' and professionals' views. Schizophrenia Bull 2006, 32:786-794.

29. McEvoy JP, Freter S, Everett G, Geller JL, Appelbaum P, Apperson LJ, Roth L: Insight and the clinical outcome of schizophrenic patients. J Nerv Ment Dis 1989, 177:48-51.

30. McEvoy JP, Apperson L, Appelbaum PS, Ortlip P, Brecosky J, Hammill K, Geller JL, Roth L: Insight in schizophrenia. Its relationship to acute psychopathology. J Nerv Ment Dis 1989, 177:43-47.

31. Buchanan A: A two-year prospective study of treatment compliance in patients with schizophrenia. Psychol Med 1992, 22:787-797.

32. David A, Buchanan A, Reed A, Almeida O: The assessment of insight in psychosis. Br J Psychiatry 1992, 161:599-602.

33. Amador XF, Flaum M, Andreasen NC, Strauss DH, Yale SA, Clark SC, Gorman $J M$ : Awareness of illness in schizophrenia and schizoaffective and mood disorders. Arch Gen Psychiatry 1994, 51:826-836.

34. Buckley PF, Wirshing DA, Bhushan P, Pierre JM, Resnick SA, Wirshing WC: Lack of insight in schizophrenia: impact on treatment adherence. CNS Drugs 2007, 21:129-141.

35. Bartkó G, Mayláth E, Herczeg l: Comparative study of schizophrenic patients relapsed on and off medication. Psychiatry Res 1987, 22:221-227. 
36. Heres S, Schmitz FS, Leucht S, Pajonk FG: The attitude of patients towards antipsychotic depot treatment. Int Clin Psychopharmacol 2007, 22:275-282.

37. McEvoy JP, Applebaum PS, Apperson L, Geller JL, Freter S: Why must some schizophrenic patients be involuntarily committed? The role of insight. Compr Psychiatry 1989, 30:13-17.

38. Kane JM, Mayerhoff $D$ : Do negative symptoms respond to pharmacological treatment? Br J Psychiatry Suppl 1989, 7:115-118.

39. Tattan TM, Creed FH: Negative symptoms of schizophrenia and compliance with medication. Schizophr Bull 2001, 27:149-155.

40. Sellwood W, Tarrier N: Demographic factors associated with extreme non-compliance in schizophrenia. Soc Psychiatry Psychiatr Epidemiol 1994, 29:172-177.

41. Hogan TP, Awad AG, Eastwood R: A self-report scale predictive of drug compliance in schizophrenics: reliability and discriminative validity. Psychol Med 1983, 13:177-183.

42. Xiang YT, Want CY, Si TM, Lee EH, He YL, Ungvari GS, Chiu HF, Yang SY, Chong MY, Shinfuku N, Tan CH, Kua EH, Fujii S, Sim K, Yong KH, Trivedi JK, Chung EK, Udomratn P, Chee KY, Sartorius N: Sex differences in use of psychotropic drugs and drug-induced side effects in schizophrenia patients: findings of the Research on Asia Psychotropic Prescription (REAP) studies. Aust NZ J Psychiatry 2011, 45:193-198.

43. Pristach CA, Smith CM: Medication compliance and substance abuse among schizophrenic patients. Hosp Community Psychiatry 1990 41:1345-1348

44. Sim K, Su HC, Fujii S, Yang SY, Chong MY, Si T, Ling He Y, Kee Chung E, Huak Chan Y, Shinfuku N, Hoon Tan C, Ungvari G, Baldessarini RJ: Low doses of antipsychotic drugs for hospitalized schizophrenia patients in East Asia: 2004 vs. 2001. Int J Neuropsychopharmacol 2009, 12:117-123.

45. Valenstein M, Copeland L, Owen R, Blow F, Visnic S: Delays in adopting evidence-based dosages of conventional antipsychotics. Psychiatr Serv 2001, 52:1242-1244.

46. Conley RR, Kelly D, Love RC, McMahon RP: Rehospitalization risk with second-generation and depot antipsychotics. Ann Clin Psychiatry 2003, 15:23-31.

47. Shi L, Ascher-Svanum H, Zhu B, Faries D, Montgomery W, Marder SR: Characteristics and use patterns of patients taking first-generation depot antipsychotics or oral antipsychotics for schizophrenia. Psychiatr Serv 2007, 58:482-488

48. Walkup JT, McAlpine DD, Olfson M, Labay LE, Boyer C, Hansell S: Patients with schizophrenia at risk for excessive antipsychotic dosing. J Clin Psychiatry 2000, 61:344-348.

49. Green $\mathrm{BN}$, Johnson $\mathrm{CD}$, Adams $\mathrm{A}$ : Writing narrative literature reviews for peer-reviewed journals: secrets of the trade. J Sports Chiropract Rehab 2001, 15:5-19.

50. Reeves BC, Deeks JJ, Higgins JPT, Wells GA: The Cochrane Non-Randomised Studies Methods Group: Including non-randomized studies. In Cochrane Handbook for Systematic Reviews of Interventions. 501st edition. Edited by Higgins JPT, Green S. West Sussex: John Wiley \& Sons, Ltd; 2011:13.1-13.34.

51. Stroup DF, Berlin JA, Morton SC, Olkin I, Williamson GD, Rennie D, Moher D, Becker BJ, Sipe TA, Thacker SB, Meta-analysis Of Observational Studies in Epidemiology (MOOSE) group: Meta-analysis of observational studies in epidemiology: a proposal for reporting. JAMA 2000, 283:2008-2012.

52. Brugnoli R, Novick D, Belger M, Brown J, Germani S, Donda P, Rossi A, Pancheri $\mathrm{P}$, The Italian SOHO Study Group: Effectiveness of antipsychotic treatment for schizophrenia: Italian results of the pan-European Schizophrenia Outpatient Health Outcomes (SOHO) study after 12 months. Giorn Ital Psicopat 2006, 12:283-292.

53. Brugnoli R, Novick D, Frediani S, Rossi A, Suarez D, Haro JM, The Italian SOHO Study Group: Efficacy of antipsychotic treatment in schizophrenia: results after 24 months in Italian patients in the Schizophrenia Outpatient Health Outcomes (SOHO) study. Giorn Ital Psicopat 2007, 13:330-340

54. Ciudad A, Haro JM, Alonso J, Bousoño M, Suárez D, Novick D, Gilaberte I: The Schizophrenia Outpatient Health Outcomes (SOHO) study: 3-year results of antipsychotic treatment discontinuation and related clinical factors in Spain. Eur Psychiatry 2008, 23:1-7.

55. Haro JM, Edgell ET, Frewer P, Alonso J, Jones PB; SOHO Study Group: The European Schizophrenia Outpatient Health Outcomes Study: baseline findings across country and treatment. Acta Psychiatr Scand Supp/ 2003, 107:7-15.
56. Novick D, Haro JM, Suarez D, Vieta E, Naber D: Recovery in the outpatient setting: 36-month results from the Schizophrenia Outpatients Health Outcomes (SOHO) study. Schizophrenia Res 2009, 108:223-230.

57. Lindström E, Wilderlöv B, von Knorring L: Antipsychotic drugs-a study of the prescription pattern in a total sample of patients with a schizophrenic syndrome in one catchment area in the county of Uppland, Sweden, in 1991. Int Clin Psychopharmacol 1996, 11:241-246.

58. Sim K, Su A, Ungvari GS, Fujii S, Yang SY, Chong MY, Si T, Chung EK, Tsang HY, Chan YH, Shinfuku N, Tan CH: Depot antipsychotic use in schizophrenia: an East Asian perspective. Hum Psychopharmacol 2004, 19:103-109.

59. Owen R, Fischer EP, Kirchner JAE, Thrush CR, Williams DK, Cuffel BJ, Elliott CE, Booth BM: Clinical practice variations in prescribing antipsychotics for patients with schizophrenia. Am J Med Qual 2003, 18:140-146.

60. Bitter I, Chou JC, Ungvari GS, Tang WK, Xiang Z, Iwanami A, Elliott CE, Booth BM: Prescribing for inpatients with schizophrenia: an international multi-center comparative study. Pharmacopsychiatry 2003, 36:143-149.

61. Chong SA, Sachdev P, Mahendran R, Chua HC: Neuroleptic and anticholinergic drug use in Chinese patients with schizophrenia resident in a state psychiatric hospital in Singapore. Aust NZ J Psychiatry 2000, 34:988-991.

62. Mamo DC, Sweet RA, Chengappa KNR, Reddy RR, Jeste DV: The effect of age on the pharmacological management of ambulatory patients treated with depot neuroleptic medications for schizophrenia and related psychotic disorders. Int J Geriatric Psychiatry 2002, 17:1012-1017.

63. Remington G, Shammi CM, Sethna R, Lawrence R: Antipsychotic dosing patterns for schizophrenia in three treatment settings. Psychiatr Serv 2001, 52:96-98.

64. Emsley R, Medori R, Koen L, Oosthuizen PP, Niehaus DJ, Rabinowitz J: Long-acting injectable risperidone in the treatment of subjects with recent-onset psychosis: a preliminary study. J Clin Psychopharmacol 2008, 28:210-213.

65. Heres S, Reichhart T, Hamann J, Mendel R, Leucht S, Kissling W: Psychiatrists' attitude to antipsychotic depot treatment in patients with first-episode schizophrenia. Eur Psychiatry 2011, 26:297-301.

66. Patel MX, Nikolaou V, David AS: Psychiatrists' attitudes to maintenance medication for patients with schizophrenia. Psychol Med 2003, 33:83-89.

67. Lehman AF, Lieberman JA, Dixon LB, McGlashan TH, Miller AL, Perkins DO: Kreyenbuhl J; American Psychiatric Association; Steering Committee on Practice Guidelines: Practice guideline for the treatment of patients with schizophrenia, 2nd edition. Am J Psychiatry 2004, 161:1-56.

68. Falkai P, Wobrock T, Lieberman J, Glenthoj B, Gattaz WF, Möller HJ, WFSBP Task Force on Treatment Guidelines for Schizophrenia: World Federation of Societies of Biological Psychiatry (WFSBP) guidelines for biological treatment of schizophrenia, part 2: long-term treatment of schizophrenia. World J Biol Psychiatry 2006, 7:5-40.

69. Heres S, Hamann J, Mendel R, Wickelmaier F, Pajonk FG, Leucht S, Kissling $W$ : Identifying the profile of optimal candidates for antipsychotic depot therapy A cluster analysis. Prog Neuropsychopharmacol Biol Psychiatry 2008, 32:1987-1993.

70. Frank AF, Gunderson JG: The role of the therapeutic alliance in the treatment of schizophrenia. Relationship to course and outcome. Arch Gen Psychiatry 1990, 47:228-236.

71. Gharabawi GM, Lasser RA, Bossie CA, Zhu Y, Amador X: Insight and its relationship to clinical outcomes in patients with schizophrenia or schizoaffective disorder receiving long-acting risperidone. Int Clin Psychopharmacol 2006, 21:233-240.

72. Stankovic Z, Britvic D, Vukovic O, Ille T: Treatment compliance of outpatients with schizophrenia: patient's attitudes, demographic, clinical and therapeutic variables. Psychiatr Danub 2008, 20:42-52.

73. Lacro JP, Dunn LB, Dolder CR, Leckband SG, Jeste DV: Prevalence of and risk factors for medication nonadherence in patients with schizophrenia: a comprehensive review of recent literature. J Clin Psychiatry 2002, 63:892-909.

74. Pinikahana J, Happell B, Taylor M, Keks NA: Exploring the complexity of compliance inschizophrenia. Issues Ment Health Nurs 2002, 23:513-528.

75. Mackay K, Taylor M, Patel MX: Medication adherence and patient choice in mental health. Br J Hosp Med (Lond) 2011, 72:6-7.

76. Fenton WS, Blyler CR, Heinssen RK: Determinants of medication compliance in schizophrenia: empirical and clinical findings. Schizophr Bull 1997, 23:637-651. 
77. Heyscue BE, Levin GM, Merrick JP: Compliance with depot antipsychotic medication by patients attending outpatient clinics. Psychiatr Serv 1998, 49:1232-1234

78. Garavan J, Browne S, Gervin M, Lane A, Larkin C, O'Callaghan E: Compliance with neuroleptic medication in outpatients with schizophrenia; relationship to subjective response to neuroleptics; attitudes to medication and insight. Compr Psychiatry 1998, 39:215-219.

79. Forkmann T, Scherer A, Boecker M, Pawelzik M, Jostes R, Gauggel S: The Clinical Global Impression Scale and the influence of patient or staff perspective on outcome. BMC Psychiatry 2011, 11:83.

80. Remington $G$, Khramov I: Health care utilization in patients with schizophrenia maintained on atypical versus conventional antipsychotics. Prog Neuropsychopharmacol Biol Psychiatry 2001, 25:363-369.

81. Kazi HA: An open clinical trial with the long-acting neuroleptic zuclopenthixol decanoate in the maintenance treatment of schizophrenia. Pharmatherapeutica 1986, 4:555-560.

82. Knudsen P, Hansen LB, Hojholdt K, Larsen NE: Long-term depot neuroleptic treatment with perphenazine decanoate II. Different depot intervals in the last 6 months of a 12 month study of 42 drug monitored psychotic patients. Acta Psychiatr Scand Supp/ 1985, 322:41-50.

83. Knudsen P, Hansen LB, Hojholdt K, Larsen NE: Long-term depot neuroleptic treatment with perphenazine decanoate I. Efficacy and side effects in a 12 month study of 42 drug monitored psychotic patients. Acta Psychiatr Scand Suppl 1985, 322:29-40.

84. Gastpar M, Masiak M, Latif MA, Frazzingaro S, Medori R, Lombertie ER: Sustained improvement of clinical outcome with risperidone longacting injectable in psychotic patients previously treated with olanzapine. J Psychopharmacol 2005, 19:32-38.

85. Ganesan S, McKenna M, Procyshyn RM, Zipursky S: Risperidone long-acting injection in the treatment of schizophrenia spectrum illnesses: a retrospective chart review of 19 patients in the Vancouver Community Mental Health Organization (Vancouver, Canada). Curr Therapeutic Res 2007, 68:409-420.

86. Mortimer AM: Symptom rating scales and outcome in schizophrenia. $\mathrm{Br} J$ Psychiatry Suppl 2007, 191:S7-S14.

87. Obermeier M, Schennach-Wolff R, Meyer S, Moller HJ, Riedel M, Krause D, Seemüller F: Is the PANSS used correctly? a systematic review. BMC Psychiatry 2011, 11:113

88. Mauri MC, Turner M, Volonteri LS, Medori R, Maier W: Dosing patterns in Europe: efficacy and safety of risperidone long-acting injectable in doses of 25, 37.5 and $50 \mathrm{mg}$. Int J Psychiatry Clin Pract 2009, 13:36-47.

89. Lasser RA, Bossie CA, Gharabawi GM, Kane JM: Remission in schizophrenia: Results from a 1-year study of long-acting risperidone injection. Schizophrenia Res 2005, 77:215-227.

90. Jørgensen A, Aaes-Jørgensen T, Gravem A, Amthor KF, Dencker SJ, Rosell I, Baastrup PC, Buckhave J, Gram LF: Zuclopenthixol decanoate in schizophrenia: serum levels and clinical state. Psychopharmacology (Berl) 1985, 87:364-367.

91. Llorca PM, Bouhours P, Moreau-Mallet V, French Investigators Group: Improved symptom control, functioning and satisfaction in French patients treated with long-acting injectable risperidone. Encephale 2008, 34:170-178

92. Kim B, Lee SH, Choi TK, Suh SY, Kim YW, Yook KH, Lee EH: Effectiveness of a combined therapy of long-acting injectable risperidone and psychosocial intervention for relapse prevention in patients with schizophrenia. Clinical Psychopharmacology and Neuroscience 2008, 6:31-37.

93. Marinis TD, Saleem PT, Glue P, Arnoldussen WJ, Teijero R, Lex A, Latif MA Medori R: Switching to long-acting injectable risperidone is beneficial with regard to clinical outcomes, regardless of previous conventional medication in patients with schizophrenia. Pharmacopsychiatry 2007 40:257-263.

94. Lee MS, Ko YH, Lee SH, Seo YJ, Kim SH, Joe SH, Han CS, Lee JH, Jung IK: Long-term treatment with long-acting risperidone in Korean patients with schizophrenia. Hum Psychopharmacol 2006, 21:399-407.

95. Mohl A, Westlye K, Opjordsmoen S, Lex A, Schreiner A, Benoit M, Bräunig P, Medori R: Long-acting risperidone in stable patients with schizoaffective disorder. J Psychopharmacol 2005, 19:22-31.

96. Lasser RA, Bossie CA, Zhu Y, Locklear JC, Kane JM: Long-acting risperidone in young adults with early schizophrenia or schizoaffective illness. Ann Clin Psychiatry 2007, 19:65-71.
97. Beauclair L, Chue P, McCormick J, Camacho F, Lam A, Luong D: Impact of risperidone long-acting injectable on hospitalisation and medication use in Canadian patients with schizophrenia. J Med Econ 2007, 10:427-442

98. Tavcar R, Dernovsek MZ, Zvan V: Chosing antipsychotic maintenance therapy - a naturalistic study. Pharmacopsychiatry 2000, 33:66-71.

99. Taylor M, Currie A, Lloyd K, Price M, Peperell K: Impact of risperidine long acting injection on resource utilization in psychiatric secondary care. J Psychopharmacol 2008, 22:128-131.

100. Leal A, Rosillon D, Mehnert A, Jarema M, Remington G: Healthcare resource utilization during 1-year treatment with long-acting, injectable risperidone. Pharmacoepidemiol Drug Saf 2004, 13:811-816.

101. Varner $V$, Hays JR, Wagner AL, Averill P: Outcome comparison of patients receiving oral or depot neuroleptic medication. Psychol Rep 2001, 89:169-174

102. Haring C, Tegeler J, Lehmann E, Ptock WD: Social aspects of therapy with depot neuroleptics in the Federal Republic of Germany. Acta Psychiatr Belg 1981, 81:189-202.

103. Tegeler J, Lehmann E: A follow-up study of schizophrenic outpatients treated with depot-neuroleptics. Prog Neuropsychopharmacol 1981, 5:79-90.

104. Muirhead D, Harvey C, Ingram G: Effectiveness of community treatment orders for treatment of schizophrenia with oral or depot antipsychotic medication: clinical outcomes. Aust NZ J Psychiatry 2006, 40:596-605.

105. Denham J, Adamson L: Long-acting phenothiazines in the prevention of relapse of schizophrenic patients. Can Psychiatr Assoc J 1973, 18:235-237.

106. Kim SH, Jung DC, Ahn YM, Kim YS: The combined use of risperidone long-acting injection and clozapine in patients with schizophrenia non-adherent to clozapine: a case series. J Psychopharmacol 2010, 24:981-986

107. Rössler W, Salize HJ, Reinhard I: Treatment with antipsychotics: the impact on the patient in the community. Eur Psychiatry 1998, 13:31s-36s.

108. Tiihonen J, Wahlbeck K, Lönnqvist J, Klaukka T, loannidis JP, Volavka J, Haukka J: Effectiveness of antipsychotic treatments in a nationwide cohort of patients in community care after first hospitalisation due to schizophrenia and schizoaffective disorder: observational follow-up study. BMJ 2006, 333:224.

109. Soni SD, Gaskell K, Reed P: Factors affecting rehospitalization rates of chronic schizophrenic patients living in the community. Schizophrenia Res 1994, 12:169-177.

110. Lasser RA, Bossie CA, Gharabawi GM, Baldessarini RJ: Clinical improvement in 336 stable chronically psychotic patients changed from oral to longacting risperidone: a 12-month open trial. Int J Neuropsychopharmacol 2005, 8:427-438

111. Gharabawi GM, Bossie CA, Zhu Y, Mao L, Lasser RA: An assessment of emergent tardive dyskinesia and existing dyskinesia in patients receiving long-acting, injectable risperidone: results from a long-term study. Schizophrenia Res 2005, 77:129-139.

112. van Os J, Bossie CA, Lasser RA: Improvements in stable patients with psychotic disorders switched from oral conventional antipsychotics therapy to long-acting risperidone. Int Clin Psychopharmacol 2004, 19:229-232.

113. Emsley R, Oosthuizen PP, Koen L, Niehaus DJ, Medori R, Rabinowitz J: Remission in patients with first-episode schizophrenia receiving assured antipsychotic medication: a study with risperidone long-acting injection. Int Clin Psychopharmacol 2008, 23:325-331.

114. Gaby N, Lefkowitz D, Israel R: Experience with fluphenazine decanoate in the management of chronic schizophrenic outpatients. N C Med J 1982, 43:641-644.

115. Hoiberg MP, Nielsen B: Antipsychotic treatment and extrapyramidal symptoms amongst schizophrenic inpatients. Nord J Psychiatry 2006 60:207-212.

116. Marchiaro L, Rocca P, LeNoci F, Longo P, Montemagni C, Rigazzi C, Bogetto F: Naturalistic, restrospective comparison between second-generation antipsychotics and depot neuroleptics in patients affected by schizophrenia. J Clin Psychiatry 2005, 66:1423-1431.

117. Ainsah O, Salmi R, Osman CB, Shamsul AS: Relationships between antipsychotic medication and anthropometric measurements in patients with schizophrenia attending a psychiatric clinic in Malaysia. Hong Kong J Psychiatry 2008, 18:23-27.

118. Deslandes PN, Thomas A, Faulconbridge GM, Davies WC: Experience with risperidone long-acting injection: results of a naturalistic observation study. Int J Psychiatry Clin Pract 2007, 11:207-221. 
119. Bloch Y, Mendlovic S, Strupinsky S, Altshuler A, Fenning S, Ratzoni G: Injections of depot antipsychotic medications in patients suffering from schizophrenia: do they hurt? J Clin Psychiatry 2001, 62:855-859.

120. Sim K, Su A, Leong JY, Yip K, Chong MY, Fujii S, Yang S, Ungvari GS, Si T, Chung EK, Tsang HY, Shinfuku N, Kua EH, Tan CH: High dose antipsychotic use in schizophrenia: findings from the REAP (Research on East Asia Psychotropic Prescriptions) Study. Pharmacopsychiatry 2004, 37:175-179.

121. Herrán A, García-Unzueta MT, Fernández-González MD, Vázquez-Barquero لـ, Álvarez C, Amado JA: Higher levels of serum copper in schizophrenic patients treated with depot neuroleptics. Psychiatry Res 2000, 94:51-58.

122. Knapp M, Windmeijer F, Brown J, Kontodimas S, Tzivelkis S, Haro JM, Ratcliffe M, Hong J, Novick D, SOHO Study Group: Cost-utility analysis of treatment with olanzapine compared with other antipsychotic treatments in patients with schizophrenia in the pan-European $\mathrm{SOHO}$ Study. PharmacoEconomics 2008, 26:341-358.

123. Marland GR, Sharkey V: Depot neuroleptics, schizophrenia and the role of the nurse: is practice evidence based? A review of the literature. J Adv Nurs 1999, 30:1255-1262.

124. National Institute for Health and Clinical Excellence: The Guidelines Manual. London:; 2011 [www.nice.org.uk].

125. Kane JM, Aguglia E, Altamura AC, Ayuso Gutiérrez JL, Brunello N, Fleischhacker WW, Gaebel W, Gerlach J, Guelfi JD, Kissling W, Lapierre YD, Lindström E, Mendlewicz J, Racagni G, Carulla LS, Schooler NR: Guidelines for depot antipsychotic treatment in schizophrenia. European Neuropsychopharmacology Consensus Conference in Siena, Italy. Eur Neuropsychopharmacol 1998, 8:55-66.

126. Keith SJ, Kane JM, Turner M, Conley RR, Narsallah HA: Academic highlights: Guidelines for the use of long-acting injectable atypical antipsychotics. J Clin Psychiatry 2004, 65:120-131.

127. Kane JM, Garcia-Ribera C: Clinical guideline recommendations for antipsychotic long-acting injections. Br J Psychiatry Supp/ 2009, 52: S63-S67.

128. Royal Australian and New Zealand College of Psychiatrists Clinical Practice Guidelines Team for the Treatment of Schizophrenia and Related Disorders: Royal Australian and New Zealand College of Psychiatrists clinical practice guidelines for the treatment of schizophrenia and related disorders. Aust N Z J Psychiatry 2005, 39:1-30.

129. Masand PS, Gupta S: Long-acting injectable antipsychotics in the elderly: guidelines for effective use. Drugs Aging 2003, 20:1099-1110.

130. Kane JM, Leucht S, Carpenter D, Docherty JP, Expert Consensus Panel for Optimizing Pharmacologic Treatment of Psychotic Disorders: The expert consensus guideline series. Optimizing pharmacologic treatment of psychotic disorders. Introduction: methods, commentary, and summary. J Clin Psychiatry 2003, 64:5-19.

131. National Collaborating Centre for Mental Health: Schizophrenia. Core interventions in the treatment and management of schizophrenia in adults in primary and secondary care. London, UK: National Institute for Health and Clinical Excellence (NICE); 2009:1-41. NICE clinical guideline No. 82.

132. Ngoh LN: Health literacy: a barrier to pharmacist-patient communication and medication adherence. J Am Pharm Assoc 2009, 49:e132-e146.

133. Charpentier A, Goudemand M, Thomas P: Therapeutic alliance, a stake in schizophrenia. Encephale 2009, 35:80-89.

134. Kerwin R: Connecting patient needs with treatment management. Acta Psychiatr Scand Supp/ 2009, 438:33-39.

135. Sernyak MJ, Dausey D, Desai R, Rosenheck R: Prescribers' nonadherence to treatment guidelines for schizophrenia when prescribing neuroleptics. Psychiatr Serv 2003, 54:246-248.

136. Kong DS, Yeo SH: An open clinical trial with the long-acting neuroleptics flupenthixol decanoate and fluphenazine decanoate in the maintenance treatment of schizophrenia. Pharmatherapeutica 1989, 5:371-379.

137. Gharabawi GM, Gearhart NC, Lasser RA, Mahmoud RA, Zhu Y, Mannaert E, Naessens I, Bossie CA, Kujawa M, Simpson GM: Maintenance therapy with once-monthly administration of long-acting injectable risperidone in patients with schizophrenia or schizoaffective disorder: a pilot study of an extended dosing interval. Ann Gen Psychiatry 2007, 6:3.

138. Walburn J, Gray R, Gournay K, Quraishi S, David AS: Systematic review of patient and nurse attitudes to depot antipsychotic medication. $\mathrm{Br} \mathrm{J}$ Psychiatry 2001, 179:300-307.

139. Patel MX, de Zoysa N, Baker D, David AS: Antipsychotic depot medication and attitudes of community psychiatric nurses. J Psychiatr Ment Health Nurs 2005, 12:237-244.
140. Přikry R, Kučerová HP, Vrzalová M, Cešková E: Role of Long-Acting Injectable Second-Generation Antipsychotics in the Treatment of FirstEpisode Schizophrenia: A Clinical Perspective. Schizophrenia Res Treat 2012, (Article ID 764769):. doi:10.1155/2012/764769.

141. Möller HJ, Llorca PM, Sacchetti E, Martin SD, Medori R, Parellada E, StoRMi Study Group: Efficacy and safety of direct transition to risperidone long-acting injectable in patients treated with various antipsychotic therapies. Int Clin Psychopharmacol 2005, 20:121-130.

142. Parellada E, Andrezina R, Milanova V, Glue P, Masiak M, Turner MS, Medori R, Gaebel W: Patients in the early phases of schizophrenia and schizoaffective disorders effectively treated with risperidone long-acting injectable. J Psychopharmacol 2005, 19:5-14

143. Llorca PM, Sacchetti E, Lloyd K, Kissling W, Medori R: Long-term remission in schizophrenia and related psychoses with long-acting risperidone: results obtained in an open-label study with an observation period of 18 months. Int J Clin Pharmacol Ther 2008, 46:14-22.

144. Haro JM, Novick D, Suarez D, Ochoa S, Roca M: Predictors of the course of illness in outpatients with schizophrenia: a prospective three year study. Prog Neuropsychopharmacol Biol Psychiatry 2008, 32:1287-1292.

doi:10.1186/1471-244X-12-122

Cite this article as: Rossi et al:: Long-acting antipsychotic drugs for the treatment of schizophrenia: use in daily practice from naturalistic observations. BMC Psychiatry 2012 12:122.

\section{Submit your next manuscript to BioMed Central and take full advantage of:}

- Convenient online submission

- Thorough peer review

- No space constraints or color figure charges

- Immediate publication on acceptance

- Inclusion in PubMed, CAS, Scopus and Google Scholar

- Research which is freely available for redistribution 